\title{
Isolated gastric band tube erosion - Unusual complication of gastric band
}

\author{
Hrishkesh Salgaonkar, Hatem Al-Saadi, Chung S Chean, Jatinder Singh, Joseph Meliak, Kanagaraj Marimuthu, Alistair Sharples, Nagam-
} mapudur Balaji, and Vittal Rao*

University Hospitals of North Midlands NHS Trust, UK

\begin{abstract}
We report a patient who underwent removal of an infected port post LAGB in another institution and subsequently presented to our unit for revision bariatric surgery. Upper GI endoscopy done as part of the work up revealed the eroded tubing in the stomach without band erosion. This was confirmed at laparoscopy and the patient underwent removal of the gastric band and subsequently revision to bypass a few months after band removal.
\end{abstract}

Abbreviations: BMI: Body mass index; LAGB: Laparoscopic Adjustable Gastric Band; GI: Gastrointestinal

\section{Introduction}

Laparoscopic adjustable gastric band (LAGB) first introduced in 1993 was a popular bariatric procedure at the time of its introduction. However, high reported complication rates of $10-26 \%$ and the availability of other effective alternatives such as sleeve gastrectomy and gastric bypass has resulted in its marked decline as a bariatric procedure. LAGB currently accounts only for $6 \%$ of all bariatric procedures [1,2]. Reported complications include band erosion (28\%), band slippage (4-13\%), port tubing disconnection (20\%), port site infection (2\%), erosion with intra gastric migration (2-4\%) and gastric perforation $(0.1-0.8 \%)$, migration into small bowel or colon causing obstruction, perforation and peritonitis [3-6]. An atypical presentation of gastric band erosion where the tube which was disconnected due to port site infection had eroded into the antrum of the stomach is hereby presented.

\section{Case report}

A 56-year-old gentleman presented to the bariatric clinic requesting revision bariatric surgery after having a LAGB in another centre 11 years back. His port was removed 12 months prior due to localised port site infection. He had an upper GI endoscopy at the time of the removal of the infected port which ruled out gastric band erosion and was advised by the surgeon to have the band removed at a later date. His BMI was 40 and his comorbidities included hypertension and dyslipidaemia.

He underwent repeat Upper GI endoscopy (12 months after the initial endoscopy at the time of removal of the infected port) in our institution as part of the workup for revisional bariatric surgery. Interestingly, this revealed eroded gastric band tubing which appeared to come from the antrum (Figure 1). There was no evidence of erosion of the gastric band into the stomach.

He underwent diagnostic laparoscopy to assess and remove the gastric band. At laparoscopy, the band was carefully dissected from the proximal stomach. The band itself was visibly infected and bile stained as evidenced by the colour (Figure 2), but there was no evidence of erosion of the band into the stomach as indicated in the upper GI endoscopy. However, when the tubing was followed distally, it was found to erode into the stomach at the region of the antrum along the lesser curvature (Figures 3-5). A methylene blue leak test on table did not reveal any obvious perforation. In view of absence of perforation, a $12 \mathrm{Fr}$ robinson drain was placed at the site of gastric erosion and he was closely monitored post operatively. He was able to tolerate oral intake the next day and was discharged from the hospital after removal of the drain. Subsequently, he underwent revision to gastric bypass after 9 months and is doing well at follow up

\section{Discussion}

Gastric band erosion is a major complication of LAGB with reported incidence varying between $0.3 \%-28 \%$ depending on the duration of follow up [7]. This can occur both in early and late settings, the latter usually at 2 years follow up. The proposed mechanisms include pressure induced gastric wall ischemia and necrosis as a result of overfilling of the band, inclusion of excess gastric wall during initial surgery and ingestion of large food boluses or foreign body rejection reaction to the band material causing weak fibrous tissue formation and eventual mural erosion [8].

To the best of our knowledge, this is the first reported case where the tubing of the band in isolation has eroded into the stomach with intact gastric band ten years after the insertion of the LAGB. Isolated port removal (leaving the band and tubing in place) is an accepted technique for managing port-site infections [9]. In our experience, this approach is not without its risks as the unattached tubing can be the

${ }^{*}$ Correspondence to: Vittal Rao, University Hospitals of North Midlands NHS Trust, UK, E-mail: rraovsr@gmail.com

Key words: gastric band, erosion, complication, band tubing

Received: October 09, 2020; Accepted: October 20, 2020; Published: October 23,2020 
cause of further complications. After initial management of infected port sites in other centres where the port was removed due to port site infection and the tubing was reduced back into the peritoneal cavity, patients have presented to our unit with intra-abdominal sepsis secondary to the port tubing causing localised peritonitis and sepsis, and small bowel obstruction due to the bowel getting entangled with the port tubing requiring emergency surgery. Similar cases have been

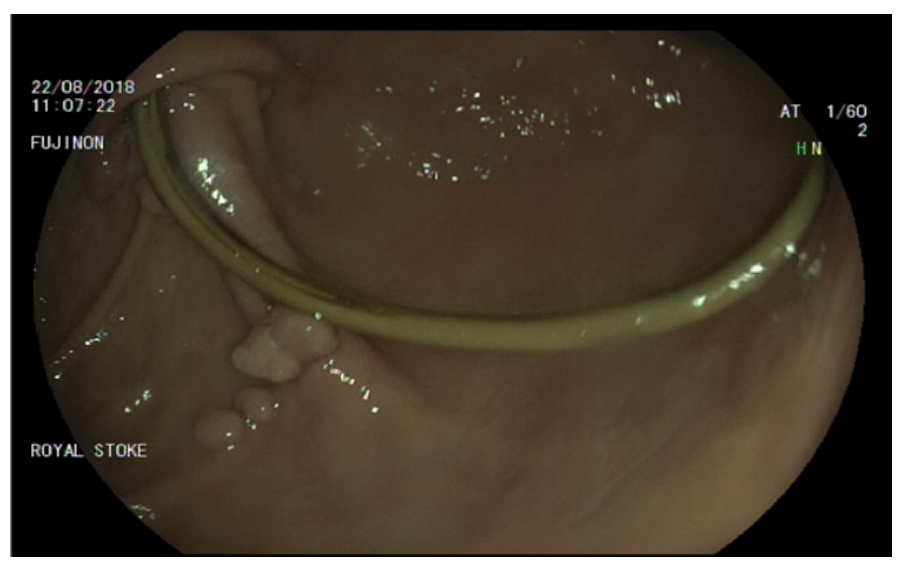

Figure 1. Erosion of the tubing at the antrum

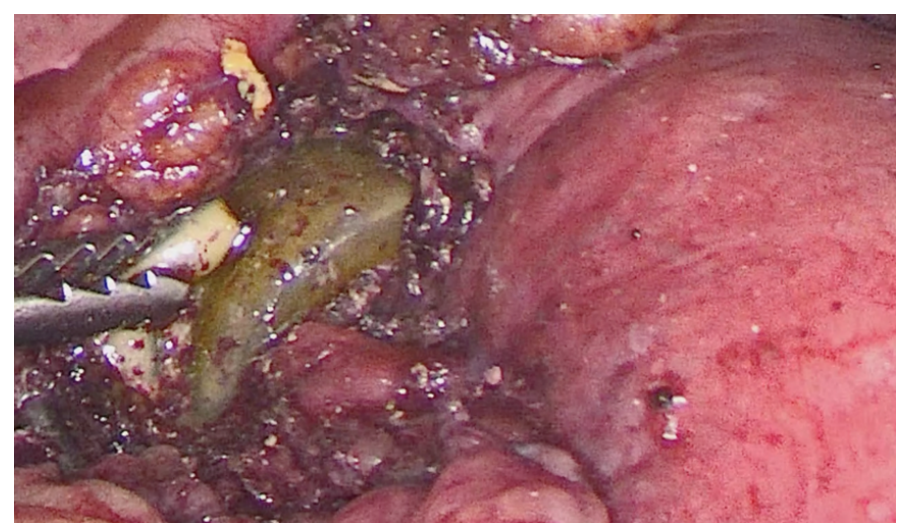

Figure 2. Gastric band being dissected off from the proximal stomach

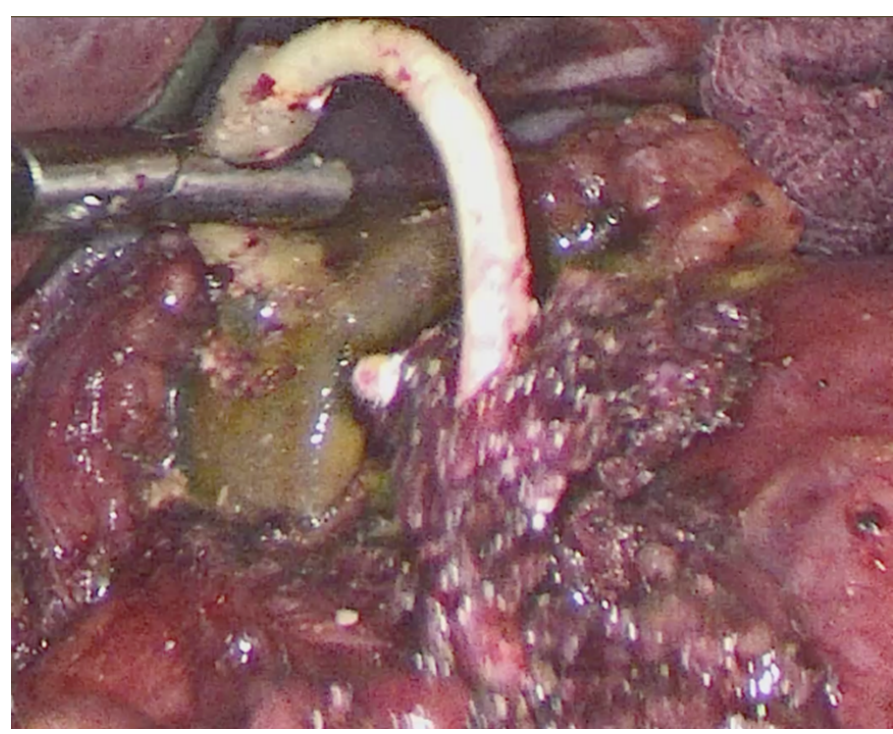

Figure 3. The tubing seen fistulating into the distal stomach in the region of the antrum

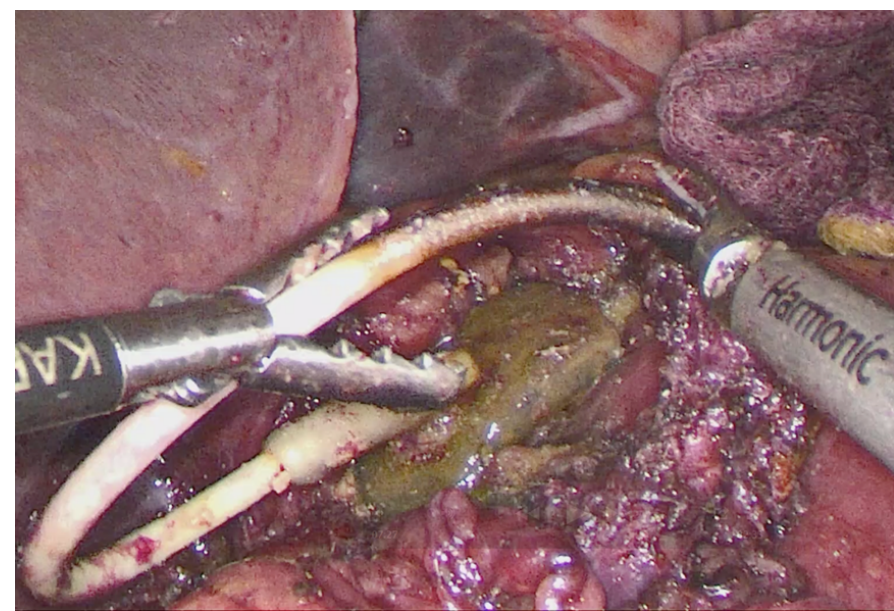

Figure 4. The tubing being gently pulled out from the gastric lumen. Note the change in colour of the tube as it emerges from the lumen indicating the site where it had eroded into the gastric lumen

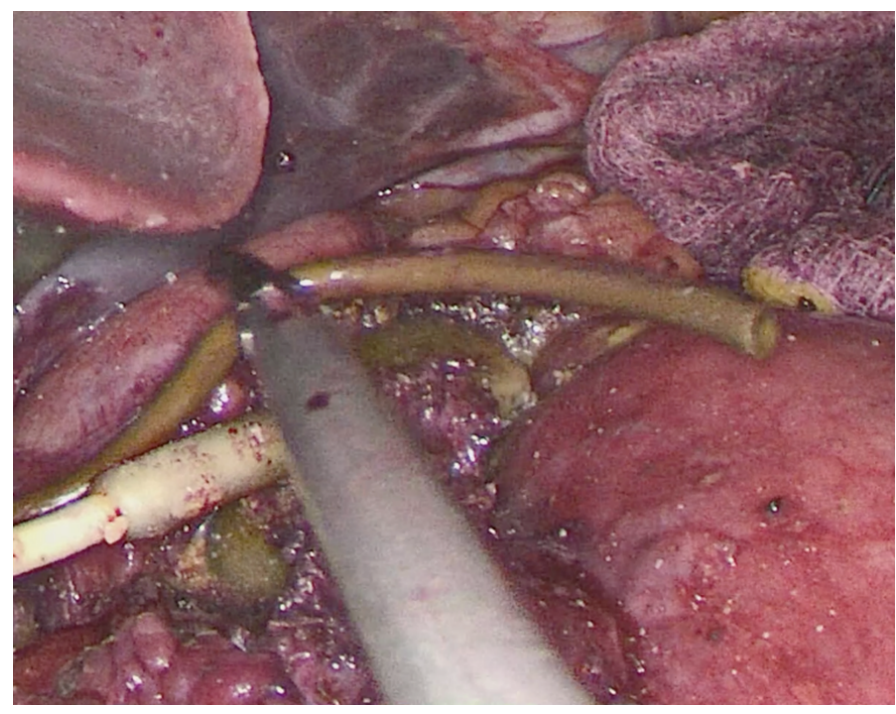

Figure 5. The tube completely withdrawn from the gastric lumen

described elsewhere in literature [10]. Additionally, a further case of tubing eroding into the small bowel has been previously described [11]. This case illustrates the importance of dealing with the entire band when patients present with port site infection. This may involve either removal of the entire band or resiting of the port rather than leaving the port tube intra abdominally which can lead to intra-abdominal sepsis or rarely erosion as illustrated in this patient.

\section{Conclusion}

Among all the complications of LAGB, erosion is a rare but the most worrisome complication which require careful management to prevent further intra-abdominal problems. In case of port site infection, it is not enough to deal with the port alone and leave the tubing inside the abdomen. A holistic approach is required and the whole band complex should be dealt with in its entirety to prevent unforeseen complications such as erosion as highlighted in this case.

\section{References}

1. Belachew M, Legrand MJ, Defechereux TH, Burtheret MP, Jacquet N (1994) Laparoscopic adjustable silicone gastric banding in the treatment of morbid obesity. A preliminary report. Surg Endosc 8: 1354-1356. [Crossref] 
2. Chevallier J-M, Zinzindohoue F, Douard R, Blanche J-P, Berta J-L, et al. (2004) Complications after laparoscopic adjustable gastric banding for morbid obesity: experience with 1,000 patients over 7 years. Obes Surg 14: 407-414. [Crossref]

3. Himpens J, Cadiere G-B, Bazi M, Vouche M, Cadiere B, et al. (2011) Long-term outcomes of laparoscopic adjustable gastric banding. Arch Surg 146: 802-807. [Crossref]

4. Povoa AA, Soares C, Esteves J, Gandra A, Maciel R, et al. (2010) Simultaneous gastric and colic laparoscopic adjustable gastric band migration. Complication of bariatric surgery. Obes Surg 20: 796-800. [Crossref]

5. Abeysekera A, Lee J, Ghosh S, Hacking C (2017) Migration of eroded laparoscopic adjustable gastric band causing small bowel obstruction and perforation. BMJ Case Rep 2017. [Crossref]

6. Brown WA, Egberts KJ, Franke-Richard D, Thodiyil P, Anderson ML, et al. (2013) Erosions after laparoscopic adjustable gastric banding: diagnosis and management. Ann Surg 257: 1047-1052. [Crossref]
7. Chapman AE, Kiroff G, Game P, Foster B, O’Brien P, et al. (2004) Laparoscopic adjustable gastric banding in the treatment of obesity: a systematic literature review. Surgery 135: 326-351. [Crossref]

8. Mozzi E, Lattuada E, Zappa MA, Granelli P, De Ruberto F, et al. (2011) Treatment of band erosion: feasibility and safety of endoscopic band removal. Surg Endosc 25: 3918-3922. [Crossref]

9. Lattuada E, Zappa M, Mozzi E, Antonini I, Boati P, et al. (2008) Injection port and connecting tube complications after laparoscopic adjustable gastric banding. Obes Surg 20: 410-4. [Crossref]

10. Hamed OH, Simpson L, Lomenzo E, Kligman MD (2013) Internal hernia due to adjustable gastric band tubing: review of the literature and illustrative case video. Surg Endosc 27: 4378-82. [Crossref]

11. Alkhaffaf B, Ammori B (2013) Fistulation of adjustable gastric band tube into small bowel. Surg Obes Relat Dis 9: 11-3. [Crossref]

Copyright: $\odot 2020$ Salgaonkar H. This is an open-access article distributed under the terms of the Creative Commons Attribution License, which permits unrestricted use, distribution, and reproduction in any medium, provided the original author and source are credited. 